\title{
Construction technique of disposable bin from sludge cake and its environmental risk
}

\author{
Udomsak Kongmuang • Duangta Kiykaew • \\ Ikuharu Morioka
}

Received: 1 August 2014/ Accepted: 3 October 2014/Published online: 7 November 2014

(C) The Japanese Society for Hygiene 2014

\begin{abstract}
Objectives Now, a lot of researchers have tried to make recycled rigid materials from the sludge cake produced in paper mill industries for the purpose of decreasing its volume. In this study, the researchers tried to make economically a disposable bin and to examine whether it is toxic or not to the outside environment.

Methods To make a disposable bin, the researchers used the sludge cake, a plastic basket, as a fixed mold, white cloth or newspaper, as a removable supporter for wrapping around the mold, and latex or plaster, as a binder. The strength of the samples was measured by tensile-stress testing. The water absorption was evaluated by Cobb test. As toxicological tests, leaching test and seed germination test were selected.

Results It was possible to form the disposal bin from the cleaned sludge cake. They seemed safe to carry garbage in the industry judging from the results of tensile-stress testing. Some of them showed less water absorptiveness (higher water resistance) in the results of Cobb test. The results of leaching test showed small values of three heavy metals, lead, nickel and copper, in the leachate. The seed germination test suggested no adverse effects of the bins in the clay and sand on the tomato growth.

Conclusions The results of these tests suggest that the bins have good strength, sufficient water resistance and no toxicological effect on the environment. This new recycled
\end{abstract}

U. Kongmuang · D. Kiykaew

Department of Sanitary Engineering, Faculty of Public Health,

Mahidol University, Bangkok, Thailand

I. Morioka $(\square)$

Graduate School of Health and Nursing Science, Wakayama Medical University, Mikazura 580, Wakayama 641-0011, Japan e-mail: moriokai@wakayama-med.ac.jp bin has the possibility to solve the environmental and health problems at disposing the sludge cake.

Keywords Paper mill $\cdot$ Sludge cake $\cdot$ Recycled bin . Lead · Toxicological effect

\section{Introduction}

Paper mill industries in Thailand generally have produced much wastewater. Since this wastewater contains a lot of organic matters, such as short fiber and heavy metals especially lead, it is usually treated both chemically and biologically $[1,2]$. Sludge cake produced after the treatments is usually burned or disposed into an industrial landfill [3].

An open industrial landfill with hazardous materials could be one of the sources of pollutants and cause environmental degeneration [3] and health problems, which significantly contribute to public health risk. It is also necessary to manage the ecological risks, such as soil erosion and water pollution [4].

Earlier studies show that sludge cake is sometimes utilized as fertilizer [5], soil conditioner [6] or fuel for combustion [7]. Now, a lot of researches have tried to make recycled rigid materials from the sludge cake [8]. They are lightweight aggregates, brick, tile, char, and slag. These are technically feasible, but not economically [8]. To reduce landfill waste and pollution emission economically, the disposable bin was designed in this study.

Converting the sludge cake into a disposable bin has three advantage points. The first one is to decrease the volume of sludge cake disposed into an industrial landfill. The second one is to decrease the usage of black plastic bag for collecting garbage in the industry. The third one is that 
all workers in the industry can use the disposable bin in any place inside the building. To dispose the new recycled bin with industrial garbage into the industrial landfill, the sludge cake should be surely shaped and safe for environment. However, there is little information on such shape forming and its environmental effects.

The aim of this study was to clarify whether the disposable bin acceptable by workers would be economically made or not and whether it is toxic or not to the outside environment considering it will be discharged outside an industrial area in the future, for example, to a municipal landfill.

\section{Methods}

\section{Cooperative industry}

The cooperative industry is a medium-sized (214 workers) paper mill industry in Thailand producing duplex board for detergent, soap and tooth paste container, etc. The wastewater is approximately $3,800-4,500 \mathrm{~m}^{3}$ in a day. The excess sludge is condensed by sludge thickener and screw press, and then becomes the sludge cake (Eurochem, Activated Sludge System). The large volume of sludge cake is disposed into the industrial landfill.

\section{Preliminary experiments}

Characteristics of the sludge cake were analyzed by Public Health and Environmental Technology Services, Faculty of Public Health, Mahidol University. The sludge cake included $23 \%$ of sludge ash in average and then volatile solids were 77 (100-23) \%. Oil and grease were $11.3 \mathrm{mg} /$ L. The concentration of lead was $0.556 \mathrm{mg} / \mathrm{L}$, the one of nickel was $0.113 \mathrm{mg} / \mathrm{L}$, and the one of copper was $1.006 \mathrm{mg} / \mathrm{L}[9]$.

The results analyzed with a fiber-length analyzer (Kajaani, FS-200) at a laboratory in Asian Institute of Technology (AIT laboratory) showed that short fibers (less than

$2.60 \mathrm{~mm}$ ) (by number of fiber) were $98.8 \%$ and long fibers were then $1.2 \%$.

The components of shape forming were a fixed mold, a removable supporter for wrapping around the mold, and a binder. In the preliminary experiment, a plastic basket was used as the fixed mold. Wasted wire screen was used for the removable supporter. Industrial latex (Thai Mitsui Specialty Chemical, Acrylax-8907) was used as the binder.

The plastic basket was wrapped outside by the coarse wire screen with approximately $25 \mathrm{~mm} \times 25 \mathrm{~mm}$ opening (Fig. 1a) and covered by the fine wire screen (mesh size number 50) (Fig. 1b). Latex was homogeneously mixed into the sludge cake in saturation volume. One hundred grams of the sludge cake needed $5 \mathrm{ml}$ of latex (latex:sludge cake 1:20). Tap water was added into the sludge cake mixed with latex to form slurry. The slurry was pasted around the fine wire screen with a trowel to about $3.5 \mathrm{~mm}$ thickness. The sample was naturally dried under the sunshine.

The slurry of sludge cake mixed with latex did not stick to the fine wire screen and flowed downward. The sample product dried slowly more than 3 days, and it then cracked (Fig. 1c). This may be resulted from two reasons. One reason was that the sludge cake contained a lot of oil, grease, rosin and alum as impurity or interference. Thus, it needs to be cleaned. The other reason was that the opening of the fine wire screen is too large. Consequently, the removable supporter was replaced in the shape-forming experiment.

\section{Shape forming}

\section{Shape-forming experiment}

The sludge cake was cleaned by tap water and was naturally dried under the sunshine for $3 \mathrm{~h}$.

A plastic basket (circular shape, $305 \mathrm{~mm}$ height, $330 \mathrm{~mm}$ top diameter and $254 \mathrm{~mm}$ bottom one) was used as the fixed mold (Fig. 2a). Used cloth or old newspaper was used as the removable supporter. Used cloth was

(b) Fine wire screen

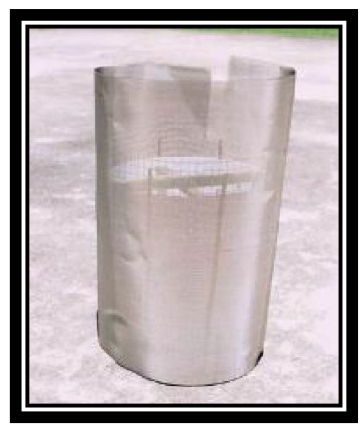

(c) Products (cracked bin)

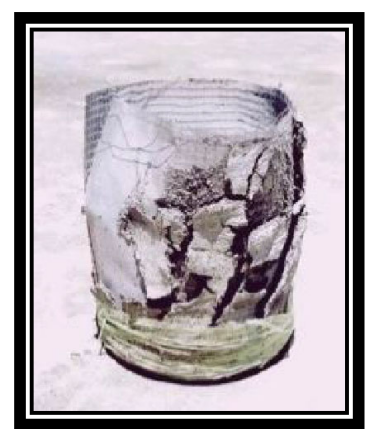

Fig. 1 Coarse wire screen (a), fine wire screen (b) and products (cracked bin) (c) of the preliminary experiment (a) Coarse wire screen

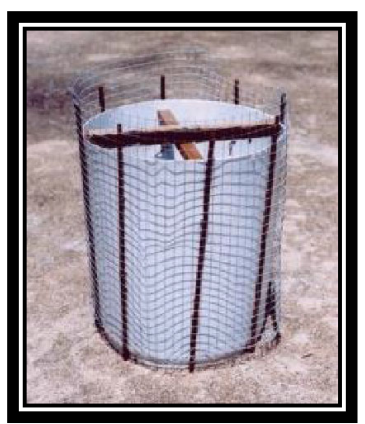


Fig. 2 A plastic basket as the fixed mold (a), used cloth as the removable supporter (b), old newspaper as the removable supporter (c) of the shapeforming experiment (a) Plastic basket

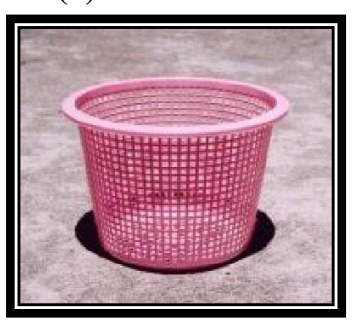

(b) Used cloth

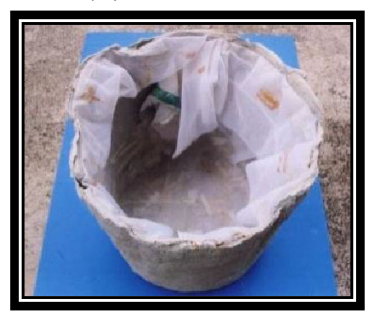

(c) Old newspaper

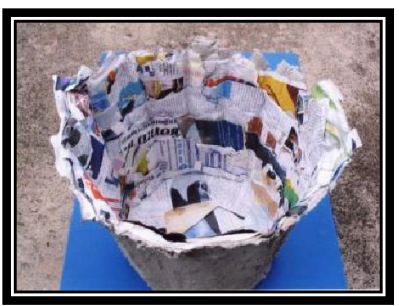

selected because of impermeability to water during pasting the slurry (Fig. 2b). Old newspaper was selected because it was easily obtained in industries and because it was cheap. It was cut into small pieces, soaked with water and then pasted on the plastic basket (Fig. 2c).

The industrial latex same as chosen in the preliminary experiments was used as the binder. Plaster (STS Gypsum Plaster, Gypsum plaster) was also selected because it was cheaper than latex. The plaster was mixed in three different weights; weight ratios between the plaster and cleaned sludge cake were 1:5, 1:10, and 1:20.

The cleaned sludge cake was mixed with the latex or the plaster. After that, it was pasted on the removable supporter around the plastic basket to the $3-5 \mathrm{~mm}$ thickness. The production was dried in open air under the sunshine $2-3 \mathrm{~h}$ a day for 1-2 days. The slurry of sludge cake was pasted again on the half dried slurry to $3-5 \mathrm{~mm}$ thickness. With same procedure, the slurry was pasted third time. The production was then dried for 3-4 weeks. The dried production was removed from the plastic basket.

\section{Strength and water absorption testing}

Flat wood was selected as the fixed mold. The used cloth and the old newspaper were selected as the removable supporter. Both flat woods and the used cloth or the old newspaper were cut into A4 size. The testing materials were made as mentioned below. The plaster at ratio 1:5, $1: 10$ or $1: 20$ or latex at saturated concentration $(1: 20)$ was mixed into the cleaned sludge cake until the slurry became homogeneous completely.

The used cloth or the old newspaper was attached to the flat wood. The slurry of sludge cake mixed with plaster or latex was pasted on it by a trowel. It was spread into uniform thickness ( $4 \mathrm{~mm}$ average) and smoothed by a wooden roller. This sample sheet was covered with thick plastic board to protect the surface and to be dried stably and slowly. Weight was measured 4-5 times until the weight became almost constant to confirm whether the sample sheets were completely dried.

During procedures, 22 sample sheets were cracked. Totally, 58 sample sheets were obtained for the strength test and the water absorption test. One combination of the (a) Latex as the binder

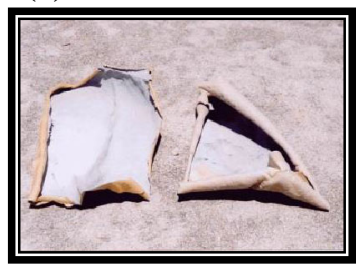

(b) Plaster as the binder

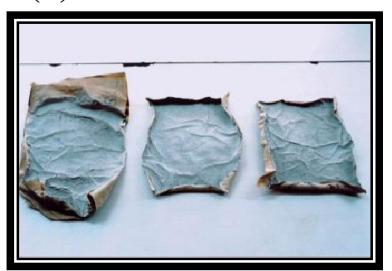

Fig. 3 Sample sheets using latex as the binder (a) and plaster as the binder (b) for strength test and water absorption test

removable supporter and the binder consisted of 6-10 sample sheets. Some of them showed the bending after unclipping the thick plastic board. The bending was greater among sample sheets using the latex (Fig. 3a) than ones using the plaster (Fig. 3b).

The strength testing was done by a tensile-stress testing machine (Toyoseiki, Pendulum type) to confirm load resistant [10]. Three sample sheets were selected from each combination. Four points were measured in each sample sheet.

The water absorption testing was made by Cobb test [11]. Cobb test is to measure weight of water absorbed into a sample in a specified time. Three sheets were generally selected from each combination. Some sample sheets using the latex were not used because of their bending.

\section{Toxicological testing}

\section{Best quality selection}

Scoring test [12] was done to identify the appropriate combination of removable supporter and binder before toxicological testing. Aspects to estimate the material were appearance, strength, water absorption and economic cost.

\section{Leaching test and seed germination test}

Three types of materials, mentioned above, were used for toxicological testing. As toxicological tests, leaching test and seed germination test were selected to confirm negative effect to the groundwater and the plant growth in the municipal landfill. 
From the results of chemical analysis in the preliminary experiments [9] lead, nickel and copper were mainly accumulated in the sludge cake. Procedures to determine these three heavy metals concentrations in the sample were total element analysis (wet digestion) [13] and leaching test under USEPA SW 846 [14]. Leaching test estimates amount of heavy metals moved out from the bin to the groundwater, when the rain would attack the bin and then infiltrate into the landfill. Three sample bins were used for this testing.

To determine the adverse effect of three heavy metals, etc., on the plant growth in the landfill, seed germination test was used [15]. Tomato was selected as the seeds and three stocks were used. Clay and sand from Lab SERD (School of Environmental Research Department, AIT Laboratory) (SERD ${ }^{\mathrm{TH}}$ soil) were used for the plant growth. This soil is an effective and economical medium for starting seeds. It is processed to balance the $\mathrm{pH}$ for optimal plant growth and hold the water yet drain well. Crushed material of bin was mixed with appropriate ratio with soil (weight of crush material:soil 1:4). Tomato seeds were planted in sand (control for pure materials of bin), crashed bins, soil on sand (control for mixed materials of bin and soil) and mixed materials of bins and soil. Observation period was set 25 days.

Eight groups were run. They were:

- Control group: sand only and soil on sand

- L bin group: crushed material using the combination of used cloth and latex without soil and one with soil

- P20 bin group: crushed material using the combination of used cloth and plaster (1:20) without soil and one with soil

- P5 bin group: crushed material using the combination of old newspaper and plaster (1:5) without soil and one with soil

Difference in the average was examined by one-way ANOVA in the seed germination test, followed by Dunnett correction for multiple comparisons.

Data handling and statistical analyses were carried out using SPSS version 19.0 (SPSS Japan). The difference was considered statistically significant for $p<0.05$.

\section{Results}

Shape forming

\section{Shape-forming experiment}

The disposable bin using old newspaper easily bended and cracked. The bin was sufficiently formed in 5 types of 8 samples shown in Table 1 . They were 4 types of the used cloth and 1 type of the old newspaper with plaster (1:5). The dried production weighed around $1.5 \mathrm{~kg}$ (Fig. 4).

\section{Strength and water absorption testing}

The results of tensile-stress test are shown in Table 2. Plaster (1:5) showed the lowest value $\left(3.37-4.76 \mathrm{~kg} / \mathrm{cm}^{2}\right)$ for tensile stress independent of using the used cloth or the newspapers. Latex showed the highest value $\left(29.32-29.86 \mathrm{~kg} / \mathrm{cm}^{2}\right)$. The lowest of Cobb value $\left(44 \mathrm{~g} / \mathrm{m}^{2}\right)$ was obtained when the used cloth and latex were used (Table 2). In contrast, plaster (1:5) showed the highest value $\left(1493\right.$ or $\left.1310 \mathrm{~g} / \mathrm{m}^{2}\right)$ independent of using the used cloth or the newspapers. The test using the old newspaper and latex was unable to be done due to the serious bended samples.

\section{Toxicological testing}

\section{Best quality selection}

The results were shown in Table 3. Total score of the combination of used cloth and latex was highest (12.5 points). Three combinations were evaluated as "not pass"

Table 1 Result of shape-forming experiment

\begin{tabular}{llll}
\hline Removable supporter & Binder (ratio) & Appearance & \\
\cline { 3 - 4 } & & Bending & Cracking \\
\hline Used cloth & Plaster $(1: 5)$ & No & No \\
Used cloth & Plaster $(1: 10)$ & Moderate & Moderate \\
Used cloth & Plaster $(1: 20)$ & Moderate & Slight \\
Used cloth & Latex $(1: 20)$ & Slight & Slight \\
Old newspaper & Plaster $(1: 5)$ & No & No \\
Old newspaper & Plaster $(1: 10)$ & Great & Great \\
Old newspaper & Plaster $(1: 20)$ & Great & Great \\
Old newspaper & Latex $(1: 20)$ & Great & Great \\
\hline
\end{tabular}

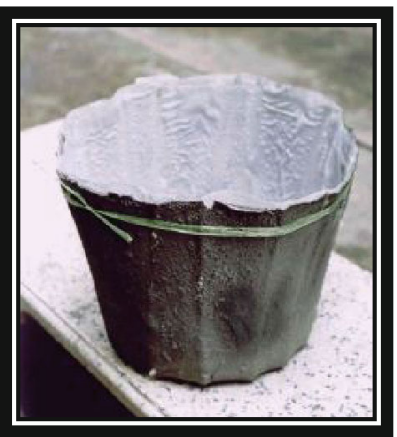

Fig. 4 Products (used cloth as the removable supporter and latex as the binder) of the shape-forming experiment 
Table 2 Result of tensile-stress test and Cobb test

Figures show the average. Ones in parentheses show the standard deviation

Table 3 Result of scoring test

\begin{tabular}{|c|c|c|c|c|c|}
\hline \multirow[t]{2}{*}{ Removable supporter } & \multirow[t]{2}{*}{ Binder (ratio) } & \multicolumn{2}{|l|}{ Tensile stress } & \multicolumn{2}{|c|}{ Cobb value } \\
\hline & & $\left(\mathrm{kg} / \mathrm{cm}^{2}\right)$ & Strength & $\left(\mathrm{g} / \mathrm{m}^{2}\right)$ & Water absorption \\
\hline Used cloth & Plaster (1:5) & $3.37(0.45)$ & Weak & 1493 & Highly \\
\hline Used cloth & Plaster (1:10) & $9.87(2.94)$ & Medium & 644 & Medium \\
\hline Used cloth & Plaster (1:20) & $11.73(0.65)$ & Strong & 250 & Little \\
\hline Used cloth & Latex $(1: 20)$ & $29.86(2.74)$ & Firmly strong & 44 & Hardly \\
\hline Old newspaper & Plaster (1:5) & $4.76(1.32)$ & Weak & 1310 & Highly \\
\hline Old newspaper & Plaster (1:10) & $5.18(0.58)$ & Weak & 581 & Medium \\
\hline Old newspaper & Plaster (1:20) & $9.00(3.57)$ & Medium & 149 & Little \\
\hline Old newspaper & Latex (1:20) & $29.32(10.80)$ & Firmly strong & - & - \\
\hline
\end{tabular}

\begin{tabular}{|c|c|c|c|c|c|c|c|}
\hline \multirow{2}{*}{$\begin{array}{l}\text { Removable } \\
\text { supporter }\end{array}$} & \multirow{2}{*}{$\begin{array}{l}\text { Binder } \\
\text { (ratio) }\end{array}$} & \multirow[t]{2}{*}{ Appearance } & \multirow[t]{2}{*}{ Strength } & \multirow{2}{*}{$\begin{array}{l}\text { Water } \\
\text { absorption }\end{array}$} & \multicolumn{2}{|c|}{ Economic cost } & \multirow{2}{*}{$\begin{array}{l}\text { Total } \\
\text { score }\end{array}$} \\
\hline & & & & & $\begin{array}{l}\text { Cost of } \\
\text { removable } \\
\text { supporter }\end{array}$ & $\begin{array}{l}\text { Cost } \\
\text { of } \\
\text { binder }\end{array}$ & \\
\hline Used cloth & Plaster (1:5) & 4 & 1 & 0 & 1 & 1 & 7 \\
\hline Used cloth & Plaster (1:10) & 1 & 2 & 1 & 1 & 1 & 6 \\
\hline Used cloth & Plaster (1:20) & 2 & 3 & 2 & 1 & 2 & 10 \\
\hline Used cloth & Latex $(1: 20)$ & 3 & 4 & 3 & 1 & 1.5 & 12.5 \\
\hline Old newspaper & Plaster (1:5) & 4 & 1 & 0 & 2 & 1 & 8 \\
\hline Old newspaper & Plaster (1:10) & 0 (not pass) & 1 & 1 & 2 & 1 & 5 (not pass) \\
\hline Old newspaper & Plaster (1:20) & 0 (not pass) & 2 & 2 & 2 & 2 & 8 (not pass) \\
\hline Old newspaper & Latex $(1: 20)$ & 0 (not pass) & 4 & - & 2 & 1.5 & - (not pass) \\
\hline
\end{tabular}

because of bending and cracking in the aspect of appearance. Judging from the total score in four aspects, the researchers selected three combinations for the toxicological testing; (a) used cloth and latex (L bin), (b) used cloth and plaster (1:20) (P20 bin), and (c) old newspaper and plaster (1:5) (P5 bin).

\section{Leaching test and seed germination test}

Table 4 shows the results of total element analysis and leaching test of three heavy metals. The results of leaching test of three heavy metals were much lower than those of total element analysis and lower than the standard of Pollution Control Department in Thailand [16].

Average number of tomato at various time of observation is shown in Table 5. The number of tomato with sand (control) reached its peak on the 10th day and then dropped on the 15 th day. On the 5 th day, the number of tomato was lower in the groups with pure material of the bin. It was zero in the groups with pure material of L bin and P20 bin. After the 10th day, however, the number of tomato increased in all bin groups. On the 20th and 25th days, the number of tomato was significantly higher in the groups with P20 bin and P5 bin than that in the control group.
With the soil on sand (control), the number of tomato was 19.0 on the 5 th day, but showed no increase. On the 5 th day, the number of tomato in the bin groups with the soil corresponded to that in the control group. After the 10th day, the number of tomato increased in all bin groups with soil, but the increase was not statistically significant. There was no significant difference compared with the control group.

\section{Discussions}

\section{Shape forming}

It was possible to form the disposable bin from the sludge cake. This may result from the short fibers in sludge cake in the paper mill industry, because paper mill sludge cake is also useful as fiber addictive for asphalt road pavement to make its stability value to high [17].

Before using the sludge cake, cleaning was necessary to remove oil, grease and the other impurities in it. This corresponded to the report that production of paperboard sometimes failed when impurities intruded the raw material [18]. The cleaned sludge cake worked well in making the disposable bin. 
Table 4 Results of total element analysis and leaching test of three heavy metals

\begin{tabular}{|c|c|c|c|c|c|c|c|c|c|}
\hline \multirow[t]{2}{*}{ Sample } & \multicolumn{3}{|c|}{ Lead (mg/L) } & \multicolumn{3}{|c|}{ Nickel (mg/L) } & \multicolumn{3}{|c|}{ Copper (mg/L) } \\
\hline & TEA & LT & $S$ & TEA & $\mathrm{LT}$ & $S$ & TEA & $\mathrm{LT}$ & S \\
\hline $\mathrm{L}$ bin & 0.45 & $<0.001$ & 0.05 & 1.49 & 0.008 & 0.05 & 1.02 & 0.004 & 1.00 \\
\hline P20 bin & 0.58 & $<0.001$ & 0.05 & 1.74 & 0.017 & 0.05 & 1.37 & 0.010 & 1.00 \\
\hline P5 bin & 1.03 & 0.002 & 0.05 & 1.18 & 0.007 & 0.05 & 9.16 & 0.012 & 1.00 \\
\hline
\end{tabular}

Figures in the TEA and LT columns show the average $(n=3)$

TEA total element analysis, $L T$ leaching test, $S$ standard value from Pollution Control Department in Thailand [16]

Table 5 Average number of tomato plant at various time of observation period

Figures show the average $(n=3)$

$* p<0.05, * * p<0.01$

(compared with 5th day)

\# $p<0.05$, \#\#\# $p<0.001$

(compared with 1: sand)

\begin{tabular}{|c|c|c|c|c|c|c|}
\hline \multirow[t]{2}{*}{ Sample no. } & \multirow[t]{2}{*}{ Treatment } & \multicolumn{5}{|c|}{ Replication (seedling) } \\
\hline & & 5th day & 10th day & 15th day & 20th day & 25 th day \\
\hline 1 & Sand (pure) & 11.0 & $34.3 *$ & 16.0 & 8.7 & 9.7 \\
\hline 2 & L bin (pure) & 0 & $11.7 *$ & $17.0 * *$ & $17.3 * *$ & $18.0 * *$ \\
\hline 3 & P20 bin (pure) & 0 & $32.3^{*}$ & $28.0^{*}$ & $37.7 * *$ & $37.0 * *$ \\
\hline \multirow[t]{3}{*}{4} & P5 bin (pure) & 11.0 & $31.7 *$ & $36.0 *$ & $37.0 *$ & $34.7 *$ \\
\hline & & $1: 2^{\#}$ & & & $1: 3^{\# \# \#}$ & $1: 3^{\#}$ \\
\hline & & $1: 3^{\#}$ & & & $1: 4^{\# \# \#}$ & $1: 4^{\#}$ \\
\hline 5 & Soil on sand & 19.0 & 17.7 & 17.0 & 14.3 & 13.0 \\
\hline 6 & L bin with soil & 14.0 & 32.3 & 32.7 & 30.0 & 27.7 \\
\hline 7 & P20 bin with soil & 17.0 & 31.7 & 28.0 & 26.3 & 25.3 \\
\hline 8 & P5 bin with soil & 14.0 & 27.3 & 27.0 & 28.7 & 28.0 \\
\hline
\end{tabular}

The researchers selected not only a circular-type, but also a rectangular-type plastic basket as the fixed mold. Using the rectangular shape, the disposable bin easily deformed at the corner. Noncircular flanges, such as rectangular frame, have to resist frame bending moments perpendicular and paralleled to the axis [19]. In contrast, the circular shape of wall can resist internal pressure equivalently. Thus, the circular type is more suitable to the fixed mold.

The slurry of sludge cake did not stick to the fine wire screen. Consequently, the removable supporter was replaced by the used cloth or the old newspaper. The old newspaper was, however, not suitable because the disposable bin used with it was easily bended and cracked. Higher amount of water is required for the proper degree of consistency of the plaster to become plastic or moldable [20]. Thus, the used cloth is more suitable because of rather impermeability to water.

Strength of the bin is one of the important properties for the use and carrying garbage. Tensile strength indicates the ability of bin to resist breaking under tension, which is dependent on the bonding strength between fibers. A lot of plaster leads the decreased proportion of short fibers in the slurry of sludge cake and then the decreased tensile strength of bin [21]. Although plaster (1:5) showed the lowest value of the tensile stress, all bins seemed safe to carry garbage in the industry judging from the values, because the bin weighted around $1.5 \mathrm{~kg}$.

Water resistance of the bin is also an important factor. Water absorptiveness provides basic information on the water resistance of bin. It was measured through direct contact of water with the surface of bin using Cobb test [22]. The lowest of Cobb value was obtained when the used cloth and the latex were used. This material seems to absorb least volume of water and then receive least effect of water. In contrast, plaster (1:5) showed the highest value independent of using the used cloth or the newspapers. This means that these materials will absorb higher volume of water and that the physical properties have the possibility to easily change. This may result from that the solubility and the porosity of gypsum plaster are high [23].

In case of using the latex (1:20), the results of tensilestress value were higher and the results of Cobb value were lower than in case using the plaster (1:20). The latex seems to bind the product stronger. Latex, compared with plaster, has the possibility to increase the setting time and decrease the values of flexural and compressive strength, and the water requirement of plaster [20]. 
Toxicological testing

Researchers selected three combinations. The L bin and the P20 bin showed good strength, and little water absorption (high water resistance). So, they can be used anywhere in an industry such as industrial kitchen, toilet or canteen. However, P5 bin showed the lowest tensile-stress value and the highest Cobb value. Those who will use this material should pay attention to the place to use it, although it is safe to carry garbage.

Concentrations of toxicants, three heavy metals (lead, nickel, and copper) were less than those reported earlier [3, $6]$. The results of leaching test showed very small values of these heavy metals in the leachate. The concentration of the lead in the leachate corresponded to that in the bottled drinking water in Japan [24]. Even if the rain would penetrate to the bins, these heavy metals will little meld out into the leachate. Although there is the possibility that these heavy metals will accumulate in the leachate, the heavy metal levels will not exceed the standard values. Thus, adverse effects of the bin disposed into the landfill on the groundwater or the infiltration will not occur.

The number of tomato in the groups with pure material of $\mathrm{L}$ bin and P20 bin on the 5th day was significantly less than that of control group. There is the possibility that the short fiber in sludge cake prevents the absorption of nitrogen, phosphorus, potassium, etc. [3], and that the used cloth and latex or plaster delay seed germination. However, when the soil was mixed, the number of tomato was corresponding to that in the control group even in such groups. The effects of used cloth and latex or plaster may not be so strong.

The number of tomato in the control group sand dropped on the 15th day. On the 20th and 25th days, the number of tomato in the groups with pure material of the bin was significantly higher than that in the control group. There was no significant effect of the crushed bins on the seed germination when the soil was mixed with. These results show that the crushed material of the bins may have the better quality than the sand (pure), and its quality has the possibility to correspond the soil for starting seed. Short fiber materials in the paper mill sludge cake play an important role for soil improvement [25]. The paper mill sludge cake may improve the properties with supplying both chemical materials as fertilizer or conditioners and good aeration [6]. Thus, even if the bins would be disposed into a landfill, not only no adverse effect but also better effect on the plant in a landfill would be expected. Further examination should be done to clarify whether tomato would be eatable or not.

The disposable bin is possible to transport. When researchers tried a preparatory test one time by putting industrial garbage into the new recycled bin, a truck driver accepted and easily dealt it without complaint. The other applications of the recycled bin are also considered, such as a durian container or a plant container.

Possible limitations of the present study should be mentioned. The sample number was three in the Cobb test, leaching test and seed germination test, although the number of data of the tensile-stress test was twelve. In the results of these tests, the researchers showed the average, but not standard deviations. There are still some disadvantages; first, because the sludge cake contains a lot of short fiber which shrinks when temperature decreases, the bin becomes reduced in size. Second, the recycled bin is handcrafted, so it is difficult to get uniform shape. Uniformity of the shape forming now requires more advanced technique.

In conclusion, sludge cake with hazardous materials, disposed into the industrial landfill, could be one of the sources of environmental and health problems. The new disposable bin can be made of the cleaned sludge cake with latex or plaster and white cloth or newspaper. It has good strength, sufficient water resistance, economic cost-benefits and no effect on the environment. This recycled bin has the possibility to solve the environmental and health problems at disposing the sludge cake.

Acknowledgments The authors wish to express the deep gratitude and appreciation to many individuals in Department of Sanitary Engineering, Faculty of Public Health, Mahidol University who contributed to the support, supervision, assistance, and insight, which facilitated the completion of this study. A very special gratitude is extended to Mr. Damri Sappanyoovith at Paper Engineering; Eastern Industrial for his idea and detailed suggestion to solve problems. The authors warmly thank Associate Professor Dr. Preeda Parkpian at the AIT laboratory for her help of shaping the research framework and patient correcting and improving the thesis. The authors wish to express their deep gratitude and appreciation to Miss Phatamarat Sartsara in Tenma Paper Mill Company (Thailand) for her kindness to allow to use the raw material and lab test.

Conflict of interest The authors declare that they have no conflict of interest.

\section{References}

1. Thompson G, Swain J, Kay M, Forster CF. The treatment of pulp and paper mill effluent: a review. Bioresour Technol. 2001;77(3):275-86.

2. Pokhrel D, Viraraghavan T. Treatment of pulp and paper mill wastewater-a review. Sci Total Environ. 2004;333(1-3):37-58.

3. Rashid MT, Barry D, Goss M. Paper mill biosolids application to agricultural lands: benefits and environmental concerns with special reference to situation in Canada. Soil Environ. 2006;25(2):85-98.

4. Krishna AK, Mohan KR. Risk assessment of heavy metals and their source distribution in waters of a contaminated industrial site. Environ Sci Pollut Res Int. 2014;21(5):3653-69.

5. Camberato JJ, Gagnon B, Angers DA, Chantigny MH, Pan WL. Pulp and paper mill by-products as soil amendments and plant nutrient sources. Can J Soil Sci. 2006;86:641-53.

6. Legendre BL, Bischoff KP, Gravois KA, Hendrick RD, Arceneaux AE. Sugarcane yields and soil analysis following 
application of paper-mill sludge. J Am Soc Sugar Cane Technol. 2004;24:60-9.

7. Shin D, Jang S, Hwang J. Combustion characteristics of paper mill sludge in a lab-scale combustor with internally cycloned circulating fluidized bed. Waste Manag. 2005;25(7):680-5.

8. Okuno N, Ishikawa Y, Shimizu A, Yoshida M. Utilization of sludge in building material. Water Sci Technol. 2004;49(10):225-32.

9. Central Laboratory, Faculty of Public Health, Mahidol University. Heavy metal analysis.

10. Wikipedia, the Free Encyclopedia, Tensile testing, http://en. wikipedia.org/wiki/Tensile_testing. Accessed 29 Sep 2014.

11. Tappi, Paper and Paperboard Testing. http://www.tappi.org/ Bookstore/Standards-TIPs/Standards/Paper-and-Paperboard.aspx. Accessed 29 Sep 2014.

12. Institute of Education Sciences U.S. Department of Education, NAEP Item Scoring Process: www.nces.ed.gov/nationsre portcard/contracts/item_score.asp. Accessed 29 Sep 2014.

13. Eaton AD, American Public Health Association (APHA), American Water Works Association (AWWA), \& Water Environment Federation (WEF). Method 3030D "Digestion for metal" (Total element analysis \& leaching test), In: Standard Methods for the examination of water \& wastewater, 21st ed. Washington, DC, APHA-AWWA-WEF, 2005.

14. US Environmental Protection Agency (USEPA). USEPA SW846: Test Methods for Evaluating Solid Waste, Physical/Chemical Methods. http://www.epa.gov/osw/hazard/testmethods/ sw846/. Accessed 29 Sep 2014.

15. Watson TT, Garden guide germination testing. http://www.gar denguides.com/3023-germination-testing.html (2014.9.29).
16. Pollution Control Department in Thailand. Environmental quality standards. 2nd ed. Bangkok: Division Office of the National Environmental Board; 1989.

17. Mari EL, Moran SR, Austria CO. Paper mill sludge as fiber addictive for asphalt road pavement. Philipp J Sci. 2009;138(1):29-36.

18. Chandra S. Impurities in phosphogypsum. In: Waste materials used in concrete manufacturing. New Jersey: Noyes Publications; 1997. p. 313-316.

19. Bickford J. 2.1 Equivalent circular flange method and Frame bending flange design method. In: Gaskets and gasketed joints. New York: Marcel Dekker Inc.; 1998. p. 488-491.

20. Colak A. Physical and mechanical properties of polymer-plaster composites. Mater Lett. 2006;60:1977-82.

21. Beer FP, Johnston ER Jr, DeWolf JT. Mechanics of materials. 4th ed. New York: McGraw-Hill Science/Engineering/Math; 2012. p. $95-6$.

22. Rhim JW, Kim JH. Properties of poly(lactide)-coated paperboard for the use of 1-way paper cup. J Food Sci. 2009;74(2):E105-11.

23. Singh M, Garg M. Relationship between mechanical properties and porosity of water-resistant gypsum binder. Cem Concr Res. 1996;26(3):449-56.

24. Yoshinaga J. Lead in the Japanese living environment. Environ Health Prev Med. 2012;17(6):433-43.

25. Takahashi Laboratory. New recycling technologies for several wastes: creation of a recycling society. http://www2.kankyo. tohoku.ac.jp/htaka/english/html/02.html. Accessed 29 Sep 2014. 